\title{
BMJ Open Benefits of medication charts provided at transitions of care: a narrative systematic review
}

\author{
Fine Michèle Dietrich (D) , Kurt E Hersberger (D) , Isabelle Arnet
}

To cite: Dietrich FM, Hersberger KE, Arnet I. Benefits of medication charts provided at transitions of care: a narrative systematic review. BMJ Open 2020;10:e037668. doi:10.1136/ bmjopen-2020-037668

- Prepublication history and additional material for this paper are available online. To view these files, please visit the journal online (http://dx.doi org/10.1136/bmjopen-2020037668).

Received 11 February 2020 Revised 28 September 2020 Accepted 29 September 2020

Check for updates

(C) Author(s) (or their employer(s)) 2020. Re-use permitted under CC BY-NC. No commercial re-use. See rights and permissions. Published by BMJ.

Pharmaceutical Science, Pharmaceutical Care Research Group, University of Basel, Basel, Switzerland

Correspondence to

Dr Isabelle Arnet;

isabelle.arnet@unibas.ch

\section{ABSTRACT}

Objectives Particularly at transitions of care points information concerning current medication tends to be incomplete. A medication chart that contains all essential information on current therapy is likely to be a helpful tool for patients and healthcare providers. We aimed to investigate any type of benefits associated with medication charts provided at transition points.

Methods A systematic review according to Preferred Reporting Items for Systematic Reviews and MetaAnalyses guidelines was performed. Two databases, two online journals and two association websites dedicated to biomedicine and pharmacy issues were consulted to identify studies for the review using the search term 'medication chart' and synonyms. We run our search from database inception up to March 2019. Studies of any study design, intervention and population which examined the effect of paper-based medication charts were included. We extracted study results narratively and coded and classified them by themes and categories inductively by using the 'framework method' with content analysis. The methodological quality of the studies was assessed using the Effective Public Health Practice Project (EPHPP) tool. Results From the 846 retrieved articles, 30 studies met the inclusion criteria, mostly from Germany (18 studies) and the USA (5 studies). Thirteen studies reported a statistically significant result. In the 'patient theme', the most obvious benefits were an increase in medication knowledge, a reduction of medication errors and higher medication adherence. In the 'interdisciplinary theme', a medication chart represented a helpful tool to increase communication and inter-sectoral cooperation between healthcare providers. In the 'theme of terms and conditions', accuracy and currency of data are prerequisites for any positive effect. The quality of the studies was classified predominantly weak mainly due to unmet good quality criteria (no randomised controlled trials study design, no reported dropouts).

Conclusion Overall, the reviewed studies suggested some benefits when using medication charts. Healthcare providers could consider using medication charts in their counselling practice. However, it is unknown whether the reported benefits lead to measurable improvement in clinical outcomes.

PROSPERO registration number

\section{INTRODUCTION}

In most countries, prescribing of medications is split between standard paper prescriptions

\section{Strengths and limitations of this study}

- The use of the Preferred Reporting Items for Systematic Reviews and Meta-Analysis and the Effective Public Health Practice Project tool to evaluate the methodological quality of each included study.

- First review that highlights the benefits of medication charts.

- It is possible that we missed studies because we did not include studies written in other languages than English or German.

- Due to the narrative nature of the data, it was not possible to perform a meta-analysis of the included studies.

The overall quality of the included studies was weak.

and electronic prescribing software systems. ${ }^{1}$ After filling their prescriptions, patients may receive written information such as product name, strength, dose frequency and additional information that is required on dispensing labels that are affixed on medication or medication containers. Further information might be already present on the package, such as indication, expiration date or storage temperature. ${ }^{2}$

In this review, a medication chart is a paper document that lists all of the patient's current medications that is, prescribed and over the counter medications. It is intended to be handed over to the patient as hardcopy and conveys information to patients and healthcare professionals (eg, doctors, nurses, physiotherapists, dentists) at transitions of care. ${ }^{3}$ Other terms are used in different countries such as medication schedule ${ }^{4}$ or personal medication list. ${ }^{5}$

Effectively, patients seldom obtain a medication chart, although the number of patients with a complex medication regimen is rising. ${ }^{6}$ Every fifth patient is reported as polymedicated, which is generally recognised as a patient using five or more medications on a daily basis. ${ }^{89}$ The prevalence of polymedication among the population older than 
65 years ranges from $26.3 \%$ in Switzerland to $52.7 \%$ in Spain. ${ }^{10}{ }^{11}$ Consequently, a medication chart could be considered a helpful tool for patients using multiple medications. ${ }^{12}$

It has been suggested that correct documentation of medications can play a crucial role in patient care, especially for the continuity of medications at care transitions. ${ }^{1314}$ Across studies, deviations between medications on file and actually taken are reported to be present for $75 \%-89 \%$ of patients in the ambulatory setting. ${ }^{15-17}$ Unintentional discrepancies have been shown to lead to poorer subjective well-being, predominantly concerning the mood ${ }^{17}$ increased risk of hospital utilisation within 30 days after discharge especially for older people ${ }^{18}$ and additional medication errors, mainly omission of a regular taken medication. ${ }^{14}$ However, the impact of medication charts is still unknown.

A medication chart should optimally represent a permanent historical and current record of all prescribed and over the counter medications. The chart should contain at least the information on active ingredients, dosage, indication and special instructions. ${ }^{19}$ Usually, a medication chart is distributed to the patient as a hardcopy at transitions of care ${ }^{20}$ However, the use of electronic medication charts in the ambulatory setting is appearing such as in Germany with a national standardised medication chart ('bundeseinheitlicher Medikationsplan'). ${ }^{19}$ A 2D data code is printed on the chart, which can be scanned and used in medical practices, pharmacies or hospitals.

The benefit of a medication chart seems intuitive. However, we found no systematic review in this area. Our review aims to evaluate the benefits of paper-based medication charts for patients and healthcare providers in daily practice.

\section{METHODS}

\section{Search strategy}

This review follows Preferred Reporting Items for Systematic Reviews and Meta-Analyses (PRISMA) guidelines for the reporting of systematic reviews. ${ }^{21}$ PubMed and Web of Science were searched for papers published in English or German, using a search strategy with synonyms of 'medication chart' (see supplemental A for the complete search string). We run our search from database inception up to March 2019.

Additionally, the websites of the WHO (www.who.int), ABDA (Bundesvereinigung Deutscher Apothekerverbände) (Federal Union of German Associations of Pharmacists: www.abda.de) and the professional newspapers PZ (Pharmaceutical newsletter: www.pharmazeutischezeitung.de) and DAZ (Newsletter for pharmacists: www. deutsche-apotheker-zeitung.de) were screened for relevant publications, as a depository of grey literature dedicated to biomedicine and pharmacy issues. We also searched references of retrieved articles.

\section{Inclusion and exclusion criteria}

A study was included if a medication chart and its practical application were explored, independently of study design and intervention. Articles, which focused on a specific population (eg, children) or indication (eg, diabetes disease), and papers focusing solely on the development or electronic version of medication charts were excluded. Although electronic medication charts are increasingly being used, we have focused on the content and benefits of the chart rather than the method of transmission. Therefore, only articles that examine paper-based plans were included in this review. All hits of the search were transferred to EndNote V.X9 and freed from duplicates. One author (FMD) examined the titles of the papers and excluded irrelevant papers. The abstract of the remaining articles was then screened. A random sample of $10 \%$ of the hits was reviewed by a second author (IA) for quality verification. FMD and IA independently reviewed the full text of the articles for final inclusion. The discrepancy was solved by discussion until consensus was obtained.

\section{Data extraction and quality assessment}

Two coauthors (IA and FMD) independently extracted the following study characteristics: first author name, year of publication, study design, population, method, aim, study results, benefits of medication charts and statistical significance ( $p$ value) if present.

Study quality was measured using the EPHPP assessment tool. ${ }^{22} 23$ Each study was rated as 'strong', 'moderate' or 'weak' by evaluating the strength of five quality criteria: selection bias, study design, confounders, data collection methods, withdrawals/dropouts. The criterion blinding was not assessed because studies were inherently designed as open. A study was classified as 'strong' when no criterion was rated as weak; as 'moderate' when only one weak criterion was identified, and as 'weak' when more than one weak criterion was identified. The quality assessment was carried out independently by two coauthors (IA and FMD), the consensus was reached by discussion.

\section{Data analysis}

The individual results of the retrieved studies were predominantly of a descriptive nature. Thus, we chose a method of qualitative research to analyse the data, that is the 'framework method'. ${ }^{24}$ This methodology involves five stages to collect and analyse data. Stage 1 (transcription) was omitted as the result section of the retrieved studies were considered as transcripts. After familiarisation of the raw data (stage 2), an analytical framework was identified (stage 3) from the emerging themes, and categories were developed, all linked to positive results that is, benefits of using medication charts. Open coding (stage 4) was then performed in an inductive manner by applying the framework to the data and labelling in order to capture a crucial concept. Additional codes were identified, which allowed for the development of the framework. Each study was coded across all categories. A codebook was developed to ensure understanding of the categories (table 1). Finally, 
Table 1 Codebook with definitions of themes, categories and populations

\section{Themes}

\begin{tabular}{|c|c|}
\hline Patient & A person who is receiving, has received or has requested healthcare ${ }^{73}$ \\
\hline Process & The act of prescribing and administering medication by health experts \\
\hline Terms and conditions & Necessary requirements (in form and content) to create and work with medication charts \\
\hline Knowledge & Patients' understanding of his/her medical treatment (factual knowledge) \\
\hline Safety & $\begin{array}{l}\text { Medication safety (freedom from preventable harm with medication use) and patient safety } \\
\text { (reduction of unsafe acts within the healthcare system, as well as the use of best practices } \\
\text { shown to lead to optimal patient outcomes) }\end{array}$ \\
\hline Purpose & The function or aim that a medication chart is fulfilling for someone \\
\hline Communication & Verbal interaction between patient and healthcare provider \\
\hline Empowerment & $\begin{array}{l}\text { Patients' individual belief in his/her own capabilities to execute courses of actions in order to } \\
\text { achieve health-related goals }{ }^{74}\end{array}$ \\
\hline Prescription & A written directive to dispense and administrate medications to a particular patient \\
\hline Patient files & $\begin{array}{l}\text { A document or a collection of documents, which contain demographic, medical and treatment } \\
\text { information about a patient }\end{array}$ \\
\hline \multicolumn{2}{|l|}{ Populations } \\
\hline $\begin{array}{l}\text { Physicians/pharmacists/ } \\
\text { hospital }\end{array}$ & $\begin{array}{l}\text { Anyone of the following healthcare providers: physicians, pharmacists, nurses, medical or } \\
\text { pharmaceutical assistant }\end{array}$ \\
\hline $\begin{array}{l}\text { Patients ambulant/nursing } \\
\text { home }\end{array}$ & $\begin{array}{l}\text { Any patient who is treated in outpatient care (including diagnosis, observation, consultation, } \\
\text { treatment, intervention and rehabilitation services) or stayed in a residential facility }{ }^{75}\end{array}$ \\
\hline $\begin{array}{l}\text { Patients hospitalised/ } \\
\text { discharged }\end{array}$ & $\begin{array}{l}\text { Any patient who stayed in a hospital (ie, inpatient facilities for } 24 \text {-hour medical and nursing care) } \\
\text { or recently terminated such a stay }\end{array}$ \\
\hline
\end{tabular}

all codes were rearranged and summarised (stage 5) in a thematic matrix. ${ }^{25}$ This 'framework method' allows for the analysis of the data both across the studies and within the themes. ${ }^{26}$ In addition, conventional content analysis was performed that is, we quantified the codes assigned to labelled texts ${ }^{27}$ in order to assess the proportion of patterns in the data. We present results of both qualitative and quantitative nature summarised within themes and categories.

\section{RESULTS}

\section{Study selection}

A total of 846 articles were identified (figure 1). After deleting 122 duplicates, a further 553 studies were excluded by screening the title. The remaining 171 articles were screened through their abstract and 60 were read as full-text. Thirty met the inclusion criteria. See online supplemental B for the PRISMA Checklist.

\section{Study characteristics}

The majority of the included studies originated from Germany (18/30 studies, 60\%), followed by the USA (5), Australia (3), UK (2), Ireland (1) and Switzerland (1). Study designs (by decreasing order of evidence ${ }^{28}$ ) were: 1 systematic review, ${ }^{29} 4$ randomised controlled trials (RCT) ${ }^{30-33} 10$ cohort studies, ${ }^{34-43} 7$ cross-sectional studies, ${ }^{5}$ 44-49 2 qualitative evaluations, ${ }^{4} 504$ surveys ${ }^{51-54}$ and 2 reports. ${ }^{55} 56$ Thirteen studies reported statistically significant results with the use of medication charts. The quality was rated as 'strong' for 2 studies, ${ }^{3031}$ as 'moderate' for 5 studies $^{32} 33353742$ and as 'weak' for 21 studies. It was impossible to assess the quality for two reports. See supplement $\mathrm{C}$ for the characteristics of all 30 studies.

\section{Framework and content analysis}

The distribution of the studies between categories, methodological quality and significance of study results are shown in figure 2. As the result of the framework analysis, four study populations were defined: 'physicians/ pharmacists/hospital' (13 studies), 'patients ambulant/ nursing home' (15), 'patients hospitalised/discharged' (6) and 'citizens' (1). The data were labelled with 69 codes, which were grouped in three themes and nine categories: 'patient' (five categories: knowledge, safety, purpose, communication and empowerment); 'process' (four categories: interdisciplinary cooperation, resources, patient files and prescription) and 'terms and conditions' with no further categories. 

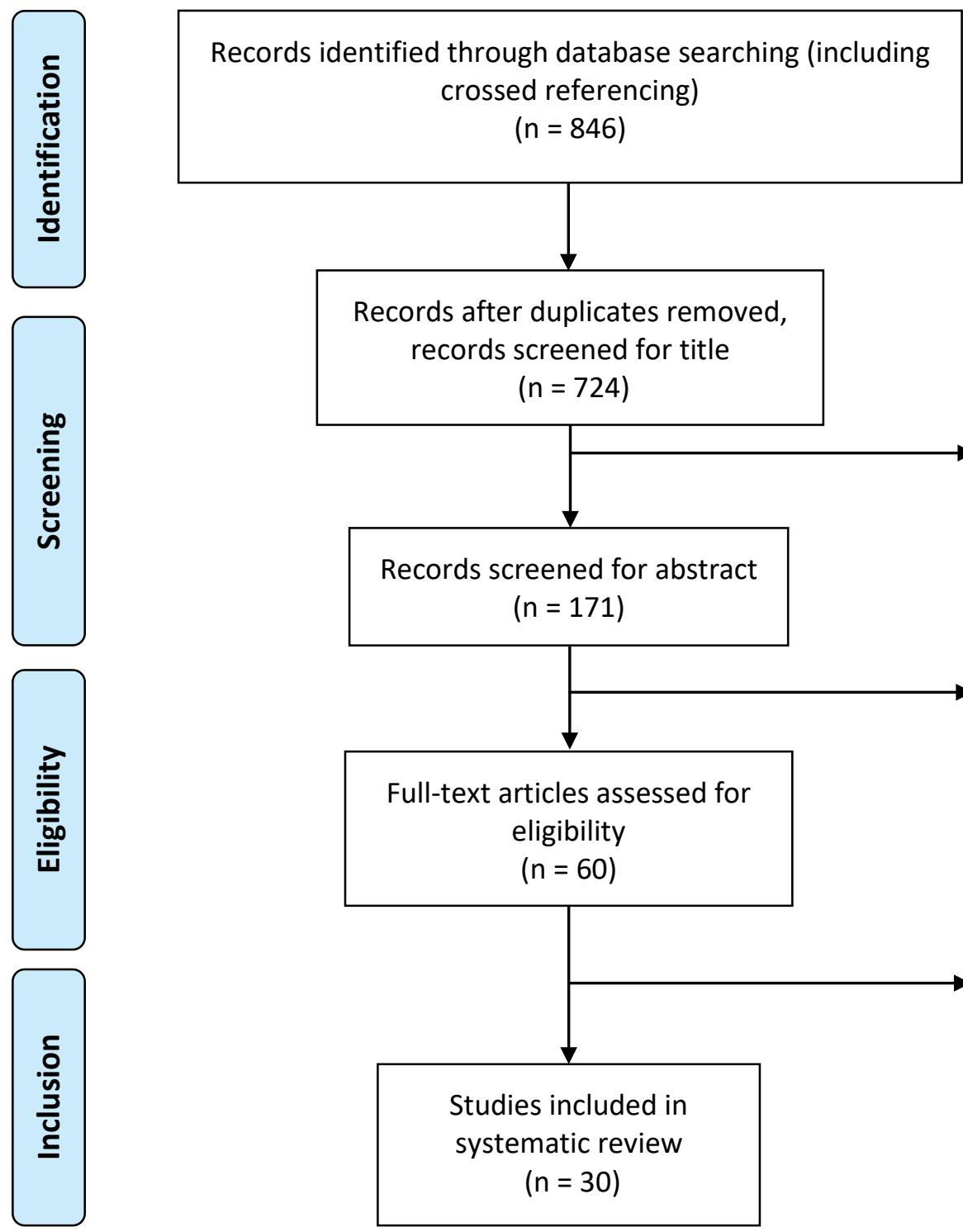

$$
(n=846)
$$
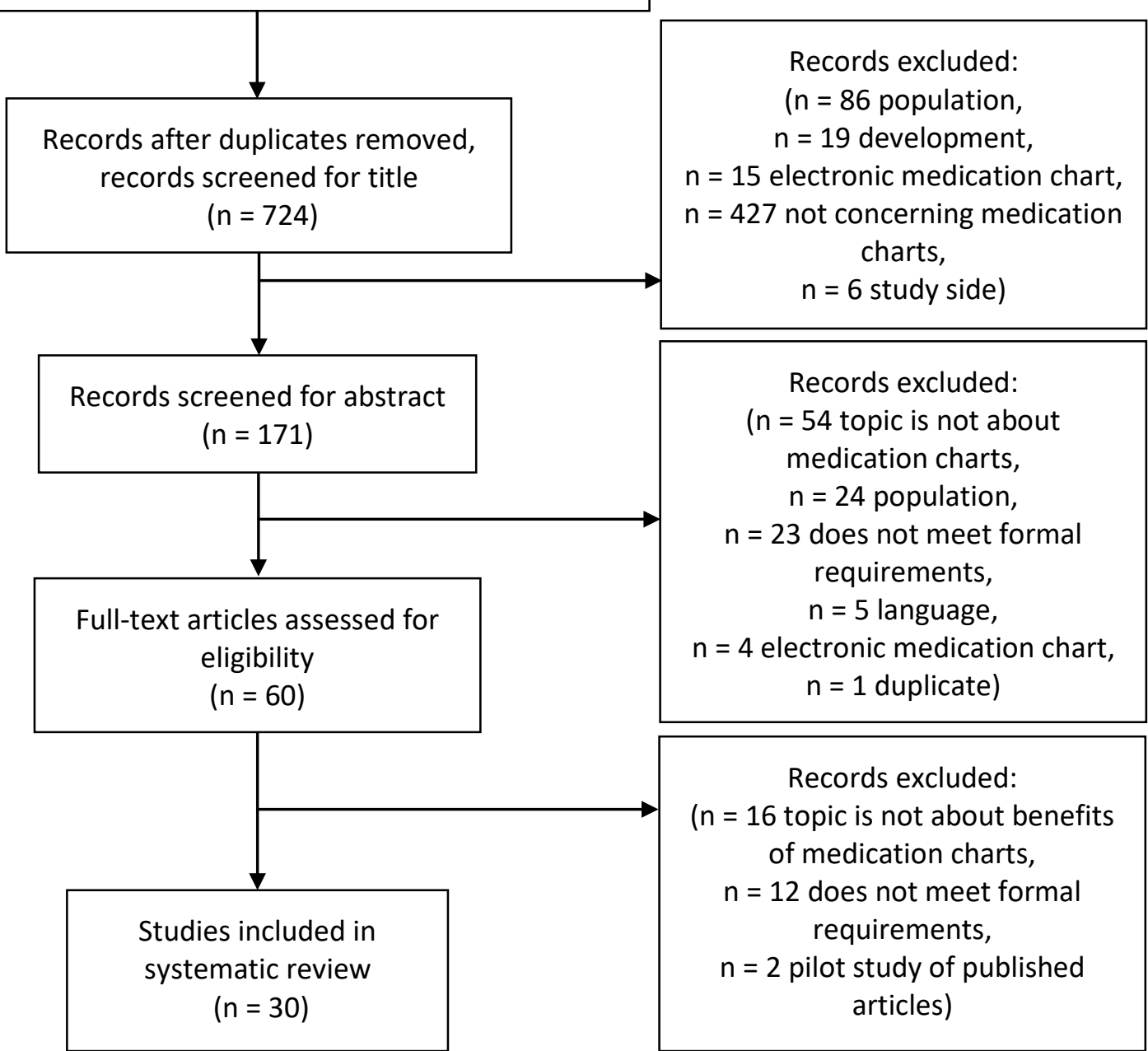

Figure 1: Flow diagram of the study selection according to PRISMA guidelines [21]

Figure 1 Flow diagram of the study selection according to Preferred Reporting Items for Systematic Reviews and MetaAnalyses guidelines. ${ }^{21}$

\section{Theme 1: 'patient'}

From the total 69 codes, $51(74 \%)$ were assigned to the theme 'patient'. They concerned mainly ambulant/ nursing home patients $(23 / 51,45 \%)$ and knowledge (18/51,35\%). Twenty-four studies $(24 / 30,80 \%)$ investigated the theme 'patient'. Two studies with strong ${ }^{3031}$ and three studies with moderate 3233 methodological quality investigated patients' knowledge. Fifty per cent (6/12) of the statistically significant results were observed in the category knowledge ${ }^{3032-343841}$ (see online supplemental D for the corresponding matrix). Patients with access to a medication chart had a better knowledge of their medication that concerned knowledge of indication, 303334364142465153 medication name, ${ }^{343846}$ dosage 313234465153 and dosage frequency. ${ }^{30-3246}$ The increase in knowledge was reported by means of patients who answered all questions correctly 


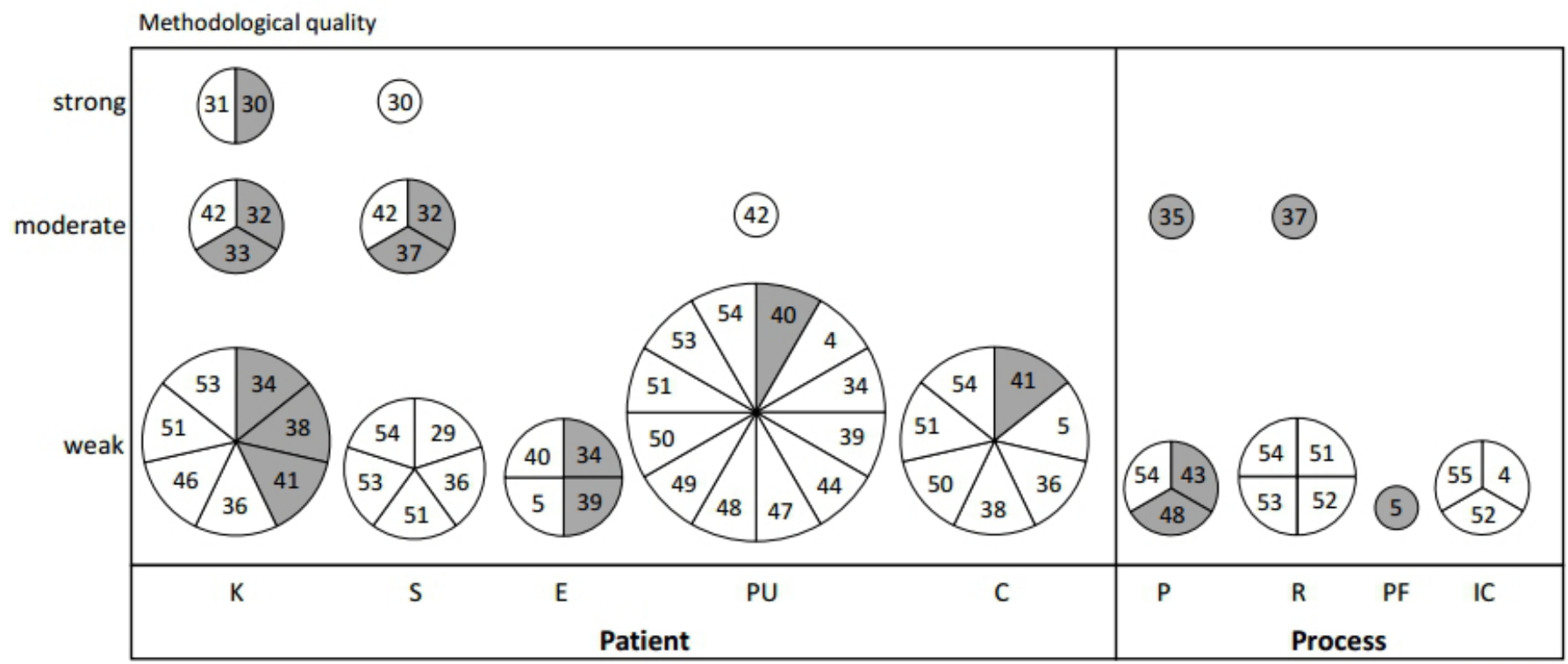

category

Figure 2 Distribution of the 30 studies between the themes 'patient' and 'process' and per category according to the methodological quality (weak, moderate, strong). Each study is represented as a pie segment (reference number), grey-shaded segments point out statistically significant study results $(p<0.05)$. The larger the pie, the larger the number of studies reporting on that category. C, communication; E, empowerment; IC, interdisciplinary cooperation; K, knowledge; P, prescription; PF, patient file; PU, purpose; R, resources; S, safety.

as follows (intervention group vs control group): $83 \%$ $(81 / 98)$ vs $47 \%(47 / 99 ; \mathrm{p}<0.001),{ }^{32} 66 \%(48 / 73)$ vs $35 \%(37 / 106 ; \mathrm{p}<0.001),{ }^{38} 60 \%(24 / 40)$ vs $17.9 \%(5 / 28$; $\mathrm{p}=0.001) .{ }^{41}$ Similarly, using medication charts increased perceived knowledge $(\mathrm{p}=0.049),{ }^{34}$ or was associated with the ability to provide correct information (OR 2.21). ${ }^{46}$ Finally, the number of correctly answered questions increased by 23.2\% (baseline 56/138; follow-up 88/138) compared with the control group (baseline 55/123; follow-up 58/126; $\mathrm{p}<0.01){ }^{33}$

In the systematic review on safety-relevant indicators, a medication chart was identified as one out of 14 parameters to ensure medication safety as well as patient safety. ${ }^{29}$ Over $80 \%$ of the patients $(\mathrm{N}=138)$ in an RCT indicated that the medication chart helped them 'avoid making mistakes with medications' that were further described as medication intake errors such as wrong time, wrong pill or missed pill. ${ }^{30}$ Another study measured a significant reduction of missed or delayed medication doses per patient after the implementation of a medication chart at discharge from hospital to nursing homes (from $37 / 202 ; 18.3 \%$ missed or delayed doses, to $6 / 226 ; 2.7 \%$, $\mathrm{p}<0.001) .{ }^{37}$ One-third of physicians and pharmacists $(11 / 34 ; 32.4 \%)$ stated in a survey that a medication chart allowed them to detect contraindications, adverse drug events and medication errors in every fifth patient. ${ }^{36}$ Medication adherence, measured by pill count, increased from $86 \%$ without a medication chart ( $\mathrm{N}=99)$ to $93 \%$ with a medication chart $(\mathrm{N}=98, \mathrm{p}<0.001){ }^{32}$ The majority of patients $(71 / 103,68.9 \%)$ mentioned that they felt safer in the handling of their medical treatment when using a medication chart. ${ }^{51}$ The purpose of a medication chart was referred as a reminder aid, ${ }^{4954}$ a documentation tool $^{47-4954}$ and a source of information. ${ }^{3454}$ The medication chart was further described as a support for transferring written information into practice (ie, preparing a pillbox). ${ }^{42} 445153$ In six studies it was suggested that the medication chart represented an important tool for a structured counselling interview between a patient and a physician or pharmacist. ${ }^{5363815051}$ The time spent on individual medications increased significantly when using a medication chart by $61.7 \%$ (from $2.13 \mathrm{~min} \quad(\mathrm{~N}=50)$ to $3.18 \min (\mathrm{N}=40), \mathrm{p}=0.02){ }^{41}$ The amount of overall information on medications and medication application given to patients increased significantly by using a medication chart (151/201 drugs, $75.1 \%$ without vs $176 / 208$, $84.6 \%$ with medication chart, $\mathrm{p}=0.017) .{ }^{41}$ When generating a medication chart, $58.3 \%$ of the surveyed physicians (21/36) conducted additional counselling with their patients. ${ }^{36}$ Empowerment of the patient was the only category that was solely reported by one population (patients ambulant/nursing home). One study reported quantitatively that patients have less concerns $(p<0.01)$ and increased perceived necessity of their medication $(p<0.01)$ when they possess a comprehensive medication chart. ${ }^{39}$ It further gave patients a more active role ${ }^{40}$ and made them feel more responsible for their medical treatment. $^{534}$

\section{Theme 2: 'process'}

From the total 69 codes, 13 (19\%) were assigned to the theme 'process'. They were reported by the two populations 'physicians/pharmacists/hospital' and 'citizens' (see online supplemental $\mathrm{E}$ for the corresponding 
matrix). Healthcare providers rated the medication chart as very important $(21 / 28,75 \%)$ or important $(7 / 28,25 \%)$ to improve communication and interdisciplinary cooperation. ${ }^{51}$ The majority of surveyed physicians $(7 / 10,70 \%)$ and pharmacists $(7 / 8,88 \%)$ stated that with a medication chart they learnt more about medications and diagnoses from other physicians or specialists. ${ }^{52}$ No economic benefit was measured, but healthcare providers expected time and money savings once the medication chart was integrated in patient care ${ }^{52}$ Healthcare providers rated the medical treatment as more appropriate (22/28, $78.6 \%$ ) according to guidelines when a medication chart was available. ${ }^{51}$ Patient files were more likely to be accurate and up-to-date with the implementation of a medication chart (328/596, 55\% correct files before and 429/594, $72 \%$ after implementation, $\mathrm{p}<0.001) .{ }^{5}$ With a medication chart, the number of patients who were receiving medications to which they had a previous adverse drug reaction decreased by $59 \%$ (from $21 / 185$ patients $(11.3 \%$ ), to $9 / 197$ patients $(4.6 \%), p=0.021) .{ }^{35}$ Furthermore, the continuity of medication management was increased when a medication chart was available at hospital admission (medications continued at hospital admission: $197 / 493,40 \%$ without vs $799 / 1510,53 \%$ with medication chart, $\mathrm{p}<0.001) .{ }^{43}$ At hospital admission, the number of missing doses of the current treatment decreased from 2.35 to $0.24 \quad(\mathrm{p}<0.05)$ per patient after implementing medication charts. ${ }^{48}$

\section{Theme 3: 'terms and conditions'}

From the total 69 codes, 5 (7\%) were assigned to the theme 'terms and conditions', for example the possession of a medication chart and its active use being a prerequisite to any benefit. ${ }^{46}$ Two studies concluded that just the delivery of a medication chart to a patient is not sufficient to improve medication safety. ${ }^{44}{ }^{54}$ It is also essential to inform the patient about how to use the medication chart and why it is needed. ${ }^{54}$ Further, it has been suggested that a medication chart has to be accurate, up-to-date and comprehensive to achieve the benefits. ${ }^{446}$ One study observed that only $6.5 \%(26 / 399)$ of the available charts were free of discrepancies. At least one prescription medication was missing on every second medication chart according to that study. ${ }^{49}$ It was reported that laboratory values such as international normalised ratio (INR) helped to have the measured values under control when documented on the chart. INR values $>5$ decreased by $23 \%$ (from $1.9 \%, \mathrm{~N}=14405$ INRs, to $1.45 \%, \mathrm{~N}=15$ 090 INRs) after implementation of a medication chart $(\mathrm{p}=0.004) .^{35}$

\section{DISCUSSION}

The 'framework method' was used to analyse the results of 30 studies as it enables a thematic analysis of qualitative data and has been previously used in studies with diaries. ${ }^{57}$ We identified commonalities and differences in data after grouping codes around themes. The output was a matrix with rows and columns that define cells of summarised data. Within a matrix, the single result remains connected to other aspects so that the context is not lost. Thus, we generated a descriptive overview of the entire data sets and comparison within cells as well as across cells was easy.

This study highlights a wide range and number of potential benefits when using medication charts in daily practice, concerning the themes 'patients', 'process' and 'terms and conditions'. Unsurprisingly, a medication chart is seen by patients and healthcare providers as an essential source of information and knowledge regarding individual medication. Specifically, for patients, a medication chart represents an additional reminder aid and provides support for communication with healthcare providers. For healthcare providers, a medication chart improves the quality of their own records and interdisciplinary cooperation. However, in order for patients with polypharmacy to benefit from a medication chart, accuracy and currency of data were of utmost importance.

Most statistically significant results were observed in the category 'knowledge', although its definitions varied considerably between studies. There were various different methods for measuring knowledge used in the retrieved studies, such as an Evaluation Tool to quantify comprehension of the medication chart. ${ }^{44}$ However, in some papers knowledge, a very complex concept, was measured using not validated or reliable simple instruments such as open questions in a structured phone interview. ${ }^{30}$ Nevertheless, the benefit of a medication chart on patients' knowledge has been recognised by both, physicians and pharmacists, as demonstrated in prospective studies. $^{53}$

Medication adherence, measured by pill counting, increased from $86 \%$ to $93 \%$ for patients with a medication chart compared with patients without. ${ }^{32}$ This assessment method has several advantages (eg, cheap, easy, objective), and a main disadvantage that is, an empty pill bottle can fake a regular intake and is inclined to manipulation. ${ }^{58}$ Nevertheless, a statistical significant increase was observed, but no clinical significance. Thus, we postulate that increased medication adherence may be a result of higher knowledge about medications as this has been suggested in other studies. ${ }^{59} 60$

Another benefit reported with the use of medication charts were medication safety and patient safety, which represented the third most frequent category (9 studies) of benefits after knowledge and purpose (12 studies each). Since no gold standard exists to measure medication safety or patient safety, indirect methods and surrogate indicators of safety issues were reported, such as rate of medication errors or adverse events. Conversely, it has been reported that a higher rate of adverse drug reactions is apparent when using an inaccurate medication chart. ${ }^{61}$ The percentage of accurate medication charts has been estimated at $6.5 \% .{ }^{49}$ Reasons for this alarmingly low rate include lacking information on over-the-counter medication; insufficient communication between 
different healthcare settings or multiple physicians; and no regular update of the medication chart. ${ }^{1562}$ To reduce discrepancies, actions have been recommended such as regular medication reconciliations, and improving interprofessional communication as well as documentation of current medication. ${ }^{151762}$

We could find moderate evidence in favour of medication charts avoiding medication errors and adverse events. ${ }^{30} 353653$ These issues are important since the current situation regarding patient safety is alarming with adverse drug reactions and/or medication errors being the reason for admission to the emergency department for one out of five patients. ${ }^{63}$

A benefit only reported qualitatively and anecdotally was improved interdisciplinary cooperation. It is noteworthy that physicians and pharmacists mentioned it independently. Similar results are reported in other types of investigations where the success of a therapy increased when physicians and pharmacists worked in structured teamwork. $^{6465}$

The documentation of patients' medication appears to be crucial at any transition of care (eg, entry or discharge from hospital) and at any change of treatment (prescribing or deprescribing) to avoid medication errors, and eventually improve and ensure safety. The major proviso is that the medication charts are accurate, up to date and comprehensive.

The medication chart is already integrated in several official recommendations such as the national guideline for chronic heart failure ${ }^{66}$ or a WHO guideline on patient safety. ${ }^{67}$ However, there are various suggestions on how to improve the inclusion of medication charts in daily practice. The WHO suggests to motivate every patient to carry their medication chart with them at any time. The WHO also proposes to include information on allergies on the chart. ${ }^{67}$ Another suggestion is to establish two different versions of the medication chart, one for the patient written in a simplified language (eg, indication: heart weakness) and one for the healthcare providers with more detailed information (eg, indication: chronic heart failure). ${ }^{36}$ Another promising project currently tested in Bavaria, Germany, is the 'Electronic Medication Plan Plus' which aims to make the medication chart available for the emergency team at the accident location. ${ }^{36} 68$

\section{Study quality}

The EPHPP tool, an instrument developed to appraise and synthesise evidence for clinical practice, can be used for any public health intervention and has been developed to support the decision-making process in primary care. ${ }^{69}$ However, the appraisal criteria depend largely on the type of study and the risk of bias, following the concept of evidence-based medicine. ${ }^{70}$ The quality of our 30 retrieved studies was heterogeneous and predominantly weak. Only four randomised, controlled trials and one cohort study were of high or moderate quality. As blinding is not possible in the context of medication chart studies, we excluded it from the EPHPP criteria.
Therefore, we did not prioritise the results according to study quality and all the benefits are presented with the same importance. Whereas the results of the included quantitative studies were surely weak, the qualitative data that we analysed in this review provide more robust evidence of our findings. Therefore, the evidence for the findings of our study can be claimed as moderate.

\section{Strengths and weaknesses of the study}

This narrative systematic review has several strengths. First, this review highlights the benefits of medication charts in daily practice and therefore adds valuable information for current and further research. Second, we assessed the methodological quality of our retrieved studies by using the EPHPP tool, which was created and validated for the quality assessment of studies across the field of public health. Third, we did not include studies, which focused on specific populations or indications in order to derive findings for the general population. It is possible, but unlikely, to have missed unexpected benefits of medication charts. Finally, matrix with codes of different themes give a suitable and quick overview on the topic and provide arguments when discussing the necessity of medication charts.

This review has also some limitations. First, papers written in other languages than English or German were not searched, which may result in publication bias. Grey literature search was focused on German sources because at the time of our research, there was a political debate in Germany about the value of the recently introduced nationwide medication chart, leading to a hype media coverage. However, as the USA and Germany were among the first countries to investigate medication charts and to publish their research, we suppose that the most relevant studies were retrieved. Second, we focused on printed medication charts. There are plenty of opportunities to use electronic charts on websites (eg, 'My Medicine Record ${ }^{71}$ ) or as apps for mobile devices (eg, 'MyTherapy ${ }^{72}$ ). Electronic medication charts are likely to be increasingly implemented over the next years. Nevertheless, we postulate that the benefits observed in our study, as well as the terms and conditions surrounding the use of a medication chart, will remain independent of the format. Finally, the included studies used various methods, which partially were not validated or evaluated. Given the fact that there is no gold standard for many of the discussed topics, these diverse methods represent the current situation in this research field.

\section{CONCLUSIONS}

The reviewed studies suggested some benefits linked to the use of a medication chart for patients and healthcare providers. In some studies, patients demonstrated an increased knowledge about their medical treatment, which may be linked to a higher medication adherence. For healthcare providers, a medication chart may enable an improved interdisciplinary cooperation and represents 
a useful counselling tool with patients. Considering the overall weak study quality and the use of various data collection methods on one hand, and the more robust qualitative study results, on the other hand, we claim that evidence of our finding is moderate. Unfortunately, high-quality prospective studies on this topic are rare. Importantly, it is unknown whether the observed benefits will lead to an improvement in the clinical outcomes. For healthcare providers, several questions are still not answered satisfactorily such as who is responsible for the accuracy of the medication chart or who is in charge in case of discrepancies.

For patients and healthcare providers the benefit of using medication charts is beyond doubt. With our review, we were able to contribute moderate evidence to support this common sense. In order to provide results with enhanced evidence, we depend on further research and future studies with good quality.

Acknowledgements The authors would like to thank Emeritus Professor Shalom Benrimoj for his valuable inputs and support with the manuscript.

Contributors FMD was responsible for study design, literature research, data extraction, study quality assessment, framework analysis and manuscript preparation. IA was responsible for study design, data extraction, study quality assessment, framework analysis and manuscript preparation. KEH was responsible for study design and manuscript preparation. All authors contributed to the writing process by commenting on and editing drafts.

Funding This paper presents independent research partly funded by HCl Solutions AG (HealthCare Information) in order with the programme 'eMediPlan'.

Disclaimer The views expressed are those of the authors and not necessarily those of $\mathrm{HCl}$ Solutions AG.

Competing interests None declared.

Patient consent for publication Not required.

Provenance and peer review Not commissioned; externally peer reviewed.

Data availability statement All data relevant to the study are included in the article or uploaded as supplemental information.

Supplemental material This content has been supplied by the author(s). It has not been vetted by BMJ Publishing Group Limited (BMJ) and may not have been peer-reviewed. Any opinions or recommendations discussed are solely those of the author(s) and are not endorsed by BMJ. BMJ disclaims all liability and responsibility arising from any reliance placed on the content. Where the content includes any translated material, BMJ does not warrant the accuracy and reliability of the translations (including but not limited to local regulations, clinical guidelines, terminology, drug names and drug dosages), and is not responsible for any error and/or omissions arising from translation and adaptation or otherwise.

Open access This is an open access article distributed in accordance with the Creative Commons Attribution Non Commercial (CC BY-NC 4.0) license, which permits others to distribute, remix, adapt, build upon this work non-commercially, and license their derivative works on different terms, provided the original work is properly cited, appropriate credit is given, any changes made indicated, and the use is non-commercial. See: http://creativecommons.org/licenses/by-nc/4.0/.

ORCID iDs

Fine Michèle Dietrich http://orcid.org/0000-0002-0672-6879

Kurt E Hersberger http://orcid.org/0000-0001-8678-697X

Isabelle Arnet http://orcid.org/0000-0001-7591-4104

\section{REFERENCES}

1 Barber N, Franklin BD, Cornford T, et al. Safer, faster, better? evaluating electronic prescribing. Department of practice and policy, school of pharmacy, London, 2006. Available: https://www.who.int/
patientsafety/information_centre/reports/PS019_Barber_Final_report. pdf [Accessed 19th June 2020].

2 Khoong EC, Cherian R, Smith DE, et al. Implementation of patientcentered prescription labeling in a safety-net ambulatory care network. Am J Health Syst Pharm 2018;75:1227-38.

3 The Joint Commission. "What did the doctor say?:" Improving health literacy to protect patient safety, 2007. Available: https://psnet.ahrq. gov/issue/what-did-doctor-say-improving-health-literacy-protectpatient-safety [Accessed 19th June 2020].

4 Kenning C, Protheroe J, Gray N, et al. The potential for using a universal medication schedule (UMS) to improve adherence in patients taking multiple medications in the UK: a qualitative evaluation. BMC Health Serv Res 2015;15:94.

5 Leonhardt KK, Pagel P, Bonin D, et al. Creating an accurate medication list in the outpatient setting through a patient-centered approach. In: Henriksen K, Battles J, Keyes M, et al, eds. Advances in patient safety: new directions and alternative approaches. 3; performance and tools. Rockville (MD: Agency for Healthcare Research and Quality (US), 2008.

6 Wastesson JW, Morin L, Tan ECK, et al. An update on the clinical consequences of polypharmacy in older adults: a narrative review. Expert Opin Drug Saf 2018;17:1185-96.

7 Castioni J, Marques-Vidal P, Abolhassani N, et al. Prevalence and determinants of polypharmacy in Switzerland: data from the CoLaus study. BMC Health Serv Res 2017;17:840.

8 Guthrie B, Makubate B, Hernandez-Santiago V, et al. The rising tide of polypharmacy and drug-drug interactions: population database analysis 1995-2010. BMC Med 2015;13:74.

9 Bjerrum L, Rosholm JU, Hallas J, et al. Methods for estimating the occurrence of polypharmacy by means of a prescription database. Eur J Clin Pharmacol 1997;53:7-11.

10 Franchi C, Tettamanti M, Pasina L, et al. Changes in drug prescribing to Italian community-dwelling elderly people: the EPIFARM-Elderly project 2000-2010. Eur J Clin Pharmacol 2014;70:437-43.

11 Midão L, Giardini A, Menditto E, et al. Polypharmacy prevalence among older adults based on the survey of health, ageing and retirement in Europe. Arch Gerontol Geriatr 2018;78:213-20.

12 Wickop B, Langebrake C. [Good prescribing practice in the elderly]. Ther Umsch 2014;71:366-73.

13 Tam VC, Knowles SR, Cornish PL, et al. Frequency, type and clinical importance of medication history errors at admission to hospital: a systematic review. CMAJ 2005;173:510-5.

14 Cornish PL, Knowles SR, Marchesano R, et al. Unintended medication discrepancies at the time of hospital admission. Arch Intern Med 2005;165:424-9.

15 Bedell SE, Jabbour S, Goldberg R, et al. Discrepancies in the use of medications: their extent and predictors in an outpatient practice. Arch Intern Med 2000;160:2129-34.

16 Persell SD, Bailey SC, Tang J, et al. Medication reconciliation and hypertension control. Am J Med 2010;123:182.e9-182.e15.

17 Coletti DJ, Stephanou H, Mazzola N, et al. Patterns and predictors of medication discrepancies in primary care. J Eval Clin Pract 2015;21:831-9.

18 Coleman EA, Smith JD, Raha D, et al. Posthospital medication discrepancies: prevalence and contributing factors. Arch Intern Med 2005;165:1842-7.

19 Anlage 3 zur Vereinbarung gemäß § 31a. Abs 4 Satz 1 SGB V: Spezifikation für einen bundeseinheitlichen Medikationsplan (BMP), 2018. Available: https://www.kbv.de/media/sp/Medikationsplan_ Anlage3.pdf [Accessed 19th June 2020].

20 Korzilius H, Osterloh F. Arzneimitteltherapiesicherheit Medikationsplan Im Praxistest. Deutsches Ärzteblatt 2018;115.

21 Moher D, Liberati A, Tetzlaff J, et al. Preferred reporting items for systematic reviews and meta-analyses: the PRISMA statement. PLoS Med 2009;6:e1000097.

22 Thomas H, Ciliska D. Qualitative assessment tool for quantitative studies, 2010. Available: https://merst.ca/ephpp/ [Accessed 19th June 2020].

23 Thomas BH, Ciliska D, Dobbins M, et al. A process for systematically reviewing the literature: providing the research evidence for public health nursing interventions. Worldviews Evid Based Nurs 2004;1:176-84.

24 Gale NK, Heath G, Cameron E, et al. Using the framework method for the analysis of qualitative data in multi-disciplinary health research. BMC Med Res Methodol 2013;13:117.

25 Dunger C. Qualitative analysemethoden Im fokus I: framework analysis. Z Palliativmed 2010;12:10-11.

26 Moullin JC, Sabater-Hernández D, Benrimoj SI. Qualitative study on the implementation of professional pharmacy services in Australian community pharmacies using framework analysis. BMC Health Serv Res 2016;16:439. 
27 Erlingsson C, Brysiewicz P. A hands-on guide to doing content analysis. Afr J Emerg Med 2017;7:93-9.

28 Phillips B, Ball C, Sackett D, et al. Oxford centre for evidencebased medicine - levels of evidence, 2009. Available: https://www. cebm.net/2009/06/oxford-centre-evidence-based-medicine-levelsevidence-march-2009/ [Accessed 19th June 2020].

29 Kuske S, Lessing C, Lux R, et al. [Patient safety indicators for medication safety (AMTS-PSI): international status, transferability and validation]. Gesundheitswesen 2012;74:79-86.

30 Manning DM, O'Meara JG, Williams AR, et al. 3D: a tool for medication discharge education. Qual Saf Health Care 2007;16:71-6.

31 McManus E, McCarthy S, Carson R, et al. Impact of a universa medication schedule on rationalising and understanding of medication; a randomised controlled trial. Res Social Adm Pharm 2018:14:831-8

32 Raynor DK, Booth TG, Blenkinsopp A. Effects of computer generated reminder charts on patients' compliance with drug regimens. BMJ 1993;306:1158-61.

33 Send AFJ, Peters-Klimm F, Bruckner T, et al. A randomized controlled trial to assess the effect of a medication plan containing drug administration recommendations on patients' drug knowledge after 2 months. J Clin Pharm Ther 2017;42:69-74.

34 Chae SY, Chae MH, Isaacson N, et al. The patient medication list: can we get patients more involved in their medical care? J Am Board Fam Med 2009:22:677-85.

35 Coombes ID, Stowasser DA, Reid C, et al. Impact of a standard medication chart on prescribing errors: a before-and-after audit. Qual Saf Health Care 2009;18:478-85.

36 Dormann H, Maas R. „Erprobung eines Medikationsplanes in der Praxis hinsichtlich der Akzeptanz und Praktikabilität MetropolMediplan 2016“, 2017. Available: https://www.bundesge sundheitsministerium.de/service/publikationen/gesundheit/details. html?bmg\%5Bpubid\%5D=3126 [Accessed 19th June 2020].

37 Elliott RA, Tran T, Taylor SE, et al. Impact of a pharmacist-prepared interim residential care medication administration chart on gaps in continuity of medication management after discharge from hospital to residential care: a prospective pre- and post-intervention study (MedGap study). BMJ Open 2012;2:e000918.

38 Freyer J, Greißing C, Buchal P, et al. Entlassungsmedikation - was weiß Der patient bei Entlassung über seine Arzneimittel? Dtsch Med Wochenschr 2016;141:e150-6.

39 Jäger C, Steinhaeuser J, Freund T, et al. Medication Lists and brown bag reviews: potential positive and negative impacts on patients beliefs about their medicine. Biomed Res Int 2015;2015:1-6.

40 Kannampallil TG, Waicekauskas K, Morrow DG, et al. External tools for collaborative medication scheduling. Cogn Technol Work 2013;15:121-31.

41 Send AFJ, Schwab M, Gauss A, et al. Pilot study to assess the influence of an enhanced medication plan on patient knowledge at hospital discharge. Eur J Clin Pharmacol 2014;70:1243-50.

42 Thürmann PA, Fenske D, Brell D, et al. Abschlussbericht zum Projekt: Erprobung eines Medikationsplanes in der Praxis hinsichtlich Akzeptanz und Praktikabilität - Modellregion Erfurt, 2017. Available: https://www.bundesgesundheitsministerium.de/service/ publikationen/gesundheit/details.html?bmg\%5Bpubid\%5D=3124 [Accessed 19th June 2020].

43 Wilke D, Schiek S, Knoth H, et al. Medication plans at hospital admission - a multicentre analysis using statutory health insurance data]. Deut Med Wochenschr 2018;143:E117-24.

44 Botermann L, Monzel K, Krueger K, et al. Evaluating patients' comprehensibility of a standardized medication plan. Eur J Clin Pharmacol 2016;72:1229-37.

45 Bruhwiler L, Schonenberg S, Hersberger K, et al. Verständlichkeit und Darstellung von Medikationsplänen: Wird die Patientensicht berücksichtigt? Int J Clin Pharm-Net 2016;105:1249-54.

46 Kiel S, Hey E, Haase A, et al. [Patients Ability to Provide Information about Prescribed Drugs - a Cross-Sectional Study in Ten General Practice]. Dtsch Med Wochenschr 2018;143:e188-96.

47 Rose O, Jaehde U, Köberlein-Neu J. Discrepancies between home medication and patient documentation in primary care. Res Social Adm Pharm 2018;14:340-6.

48 Vasileff HM, Whitten LE, Pink JA, et al. The effect on medication errors of pharmacists charting medication in an emergency department. Pharm World Sci 2009;31:373-9.

49 Waltering I, Schwalbe O, Hempel G. Discrepancies on medication plans detected in German community pharmacies. J Eval Clin Pract 2015;21:886-92.

50 Blake SC, McMorris K, Jacobson KL, et al. A qualitative evaluation of a health literacy intervention to improve medication adherence for underserved pharmacy patients. J Health Care Poor Underserved 2010;21:559-67.
51 Botermann L, Schulz M, Eickhoff C, et al. Erprobung eines Medikationsplans in der Praxis hinsichtlich der Akzeptanz und Praktikabilität - Pilotuntersuchung: Lesbarkeits- und Verständlichkeitstestung, Hauptuntersuchung: PRIMA - Primärsystem-Integration des Medikationsplans mit Akzeptanzuntersuchung, 2017. Available: https://www.bundesge sundheitsministerium.de/service/publikationen/gesundheit/details. html?bmg\%5Bpubid\%5D=3130 [Accessed 19th June 2020].

52 Eickhoff C, Müller U, Strunz AK, et al. Das Projekt PRiMA Elektronische Erstellung und Aktualisierung von Medikationsplänen ALS gemeinsame Aufgabe von Ärzten und Apothekern. Dtsch Med Wochenschr 2019

53 Müller U, Schulz M, Mätzler M. [Electronically supported cooperation of physicians and pharmacists to improve medication safety in the ambulatory setting: The "Arzneimittelinitiative SachsenThüringen" (ARMIN)]. Bundesgesundheitsblatt Gesundheitsforschung Gesundheitsschutz 2018;61:1119-28.

54 Strauß B, Seidling HM, Wehrmann U, et al. [Benefits of a Medication List from a Citizen's Perspective -A Qualitative Survey]. Gesundheitswesen 2018;80:700-7.

55 Dormann H, Maas R, Eickhoff C, et al. [Standardized national medication plan : The pilot projects MetropolMediplan 2016, model region Erfurt, and PRIMA]. Bundesgesundheitsblatt Gesundheitsforschung Gesundheitsschutz 2018;61:1093-102.

56 Geschäftsbereich Arzneimittel der ABDA - Bundesvereinigung Deutscher Apothekerverbände. Grundsatzpapier zur Medikationsanalyse und zum Medikationsmanagement, 2014 Available: https://www.abda.de/fileadmin/user upload/assets/ Medikationsmanagement/Grundsatzpapier_MA__MM_GBAM.pdf [Accessed 19th June 2020].

57 Jones RK. The unsolicited diary as a qualitative research tool for advanced research capacity in the field of health and illness. Qual Health Res 2000;10:555-67.

58 Lam WY, Fresco P. Medication adherence measures: an overview. Biomed Res Int 2015;2015:1-12.

59 Col N, Fanale JE, Kronholm P. The role of medication noncompliance and adverse drug reactions in hospitalizations of the elderly. Arch Intern Med 1990;150:841-5.

60 World Health Organization. Adherence to long-term therapies evidence for action. WHO Library Cataloguing-in-Publication Data, 2003. Available: http://www.who.int/chp/knowledge/publications/ adherence_full_report.pdf [Accessed 19th June 2020].

61 Nassaralla CL, Naessens JM, Chaudhry R, et al. Implementation of a medication reconciliation process in an ambulatory internal medicine clinic. Qual Saf Health Care 2007;16:90-4.

62 Schmiemann G, Bahr M, Gurjanov A, et al. Differences between patient medication records held by general practitioners and the drugs actually consumed by the patients. Int $J$ Clin Pharmacol Ther 2012;50:614-7.

63 Dormann H, Sonst A, Müller F, et al. Adverse drug events in older patients admitted as an emergency: the role of potentially inappropriate medication in elderly people (PRISCUS). Dtsch Arztebl Int 2013;110:213-9.

64 Tobari H, Arimoto T, Shimojo N, et al. Physician-Pharmacist cooperation program for blood pressure control in patients with hypertension: a randomized-controlled trial. Am J Hypertens 2010;23:1144-52.

65 Hirsch JD, Steers N, Adler DS, et al. Primary care-based, pharmacist-physician collaborative medication-therapy management of hypertension: a randomized, pragmatic trial. Clin Ther 2014;36:1244-54.

66 Bundesärztekammer, Kassenärztliche Bundesvereinigung, Arbeitsgemeinschaft der Wissenschaftlichen Medizinischen Fachgesellschaften. Nationale VersorgungsLeitlinie Chronische Herzinsuffizienz Langfassung 2. Auflage, Version 3 AWMF-RegisterNr.: nvl-006, 2017. Available: https://www.leitlinien.de/nvl/html/nvlchronische-herzinsuffizienz/3-auflage/kapitel-1 [Accessed 19th June 2020].

67 Walton M, Woodward H, Van Staalduinen S, et al. The who patient safety curriculum guide for medical schools. Qual Saf Health Care 2010;19:542-6.

68 Zentrum für Telemedizin Bad Kissingen. Elektronischer Medikationsplan Plus, 2019. Available: https://www.ztm.de/ neuigkeiten/elektronischer-medikationsplan-plus-emp [Accessed 19th June 2020].

69 National Collaborating Centre for Methods and Tools. Quality assessment tool for quantitative studies. Available: http://www. nccmt.ca/resources/search/14 2008 [Accessed 19th June 2020]. 
70 The Centre for Evidence-Based Medicine. OCEBM levels of evidence, 2016. Available: https://www.cebm.net/2016/05/ocebmlevels-of-evidence/ [Accessed 19th June 2020].

71 FDA - US Food and Drug Administration. My medicine record, 2013. Available: https://www.fda.gov/drugs/resources-you/my-medicinerecord [Accessed 19th June 2020].

72 Smartpatient GmbH. MyTherapy APP, 2019. Available: https://www. mytherapyapp.com/de [Accessed 19th June 2020].
$73 \mathrm{CPSI}$. Welcome to the Canadian patient safety Institute, 2020. Available: https://www.patientsafetyinstitute.ca/en/Pages/default. aspx [Accessed 19th June 2020].

74 Damschroder LJ, Aron DC, Keith RE, et al. Fostering implementation of health services research findings into practice: a consolidated framework for advancing implementation science. Implement Sci 2009;4:50.

75 Free Online Palliative Care Dictionary. Pallipedia( $)$ is a registered trademark of IAHPC, 2020. Available: https://pallipedia.org/ [Accessed 19th June 2020]. 